\title{
Pain in children
}

\author{
G Allen Finley MD FRCPC FAAP
}

$\mathrm{T}^{\mathrm{h}}$ he past decade or so has seen a tremendous increase in attention to children's pain research and clinical care worldwide, culminating in the International Association for the Study of Pain Global Year Against Pain in Childhood, which began October 17, 2005 (1). The year was celebrated, among other events, with the 7th International Symposium on Pediatric Pain, held June 2006 in Vancouver, British Columbia. Thus, this seems a particularly appropriate time to devote a section of this issue of Pain Research $\mathbb{E}$ Management to a special series of papers on the topic of children's pain.

Pediatric pain research has taken too many directions to be summarized easily in a single issue of our journal. Advances have been made in many disciplines and interdisciplinary areas, in basic science, assessment and clinical management. However, we have assembled three quite disparate topics for presentation here. The first article, by Carl von Baeyer (pages 157-162), presents an eloquent review of assessment of pain in children, focusing on self-report and the use of faces scales. In my opinion, failure to recognize children's pain remains the greatest barrier to adequate care, so this work is especially relevant. The second article, by Grégoire and Frager (pages 163-171), reviews current research in pediatric palliative care, a field that is coming into its own as research groups and training programs develop across Canada and around the world. Finally, Ban Tsui (pages 173-180) elaborates on the very practical issue of precise placement of epidural catheters for pain control in children and infants. New techniques have been developed that dramatically improve the ability of the anesthesiologist to prevent pain in specific dermatomes, as well as increasing the safety of central nerve blockade in even the youngest of infants. These topics represent only three of the myriad areas of interest and concern being addressed by Canadian pain researchers.

We look forward to further advances in meeting the challenges and opportunities of pediatric pain care, and encourage all health professionals to think of pain whenever they have a clinical interaction with a child.

\section{REFERENCES}

1. IASP Global Year Against Pain in Children. <http://iasppain.org/GlobalDay-2005.htm> (Version current at July 25, 2006)

President, Special Interest Group on Pain in Childhood, International Association for the Study of Pain (www.childpain.org), and Departments of Anesthesia and Psychology, Dalhousie University, Halifax, Nova Scotia

Correspondence: Dr G Allen Finley, Department of Anesthesia, Dalhousie University, 5850 University Avenue, Halifax, Nova Scotia B3K 6R8.

Telephone 902-470-7708, fax 902-470-7709, e-mail allen.finley@dal.ca 


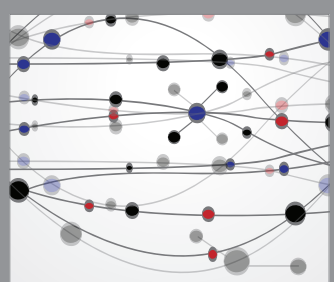

The Scientific World Journal
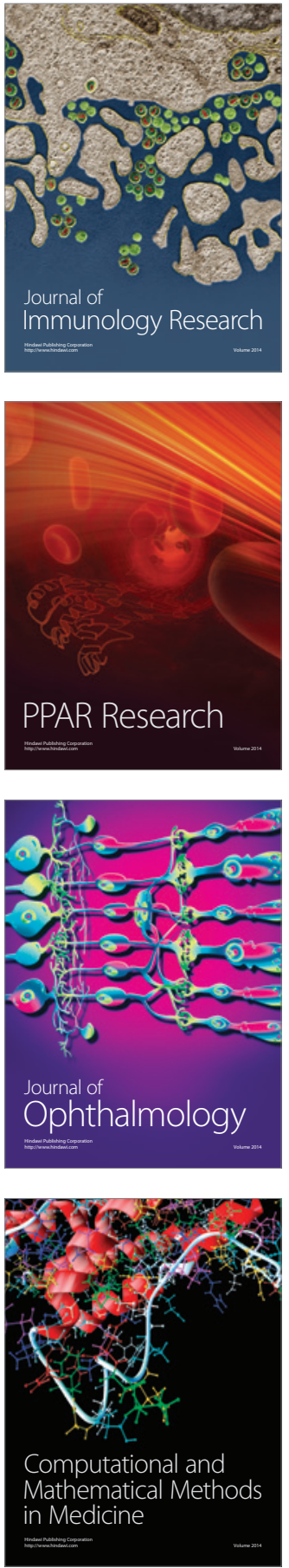

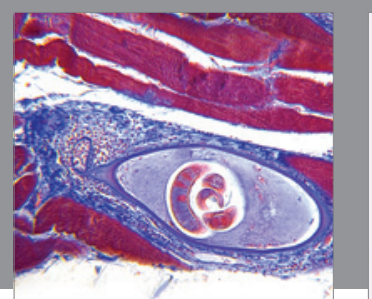

Gastroenterology Research and Practice

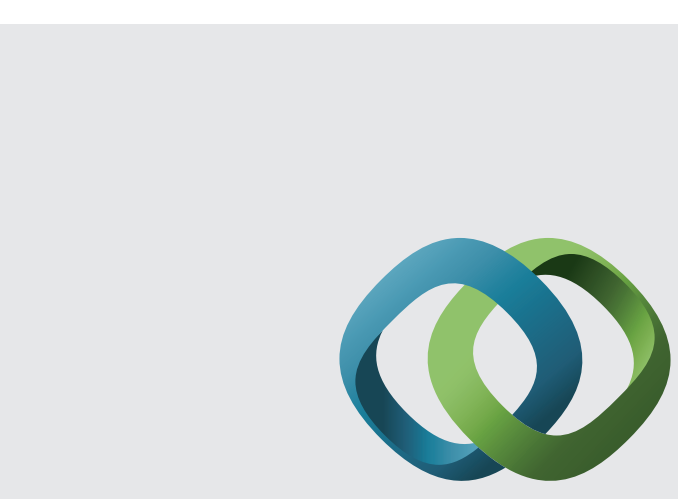

\section{Hindawi}

Submit your manuscripts at

http://www.hindawi.com
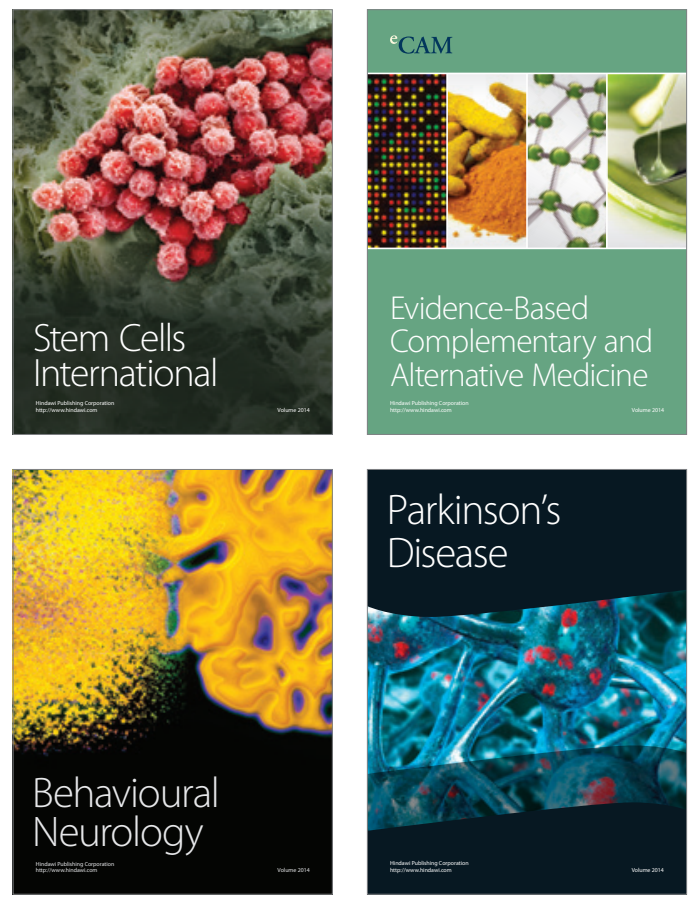
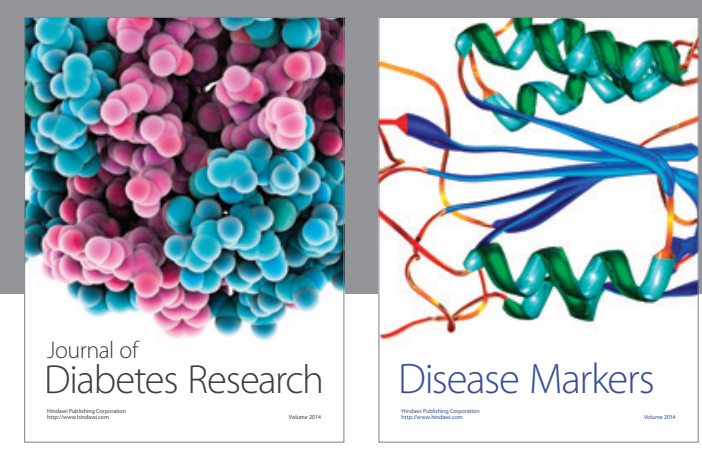

Disease Markers
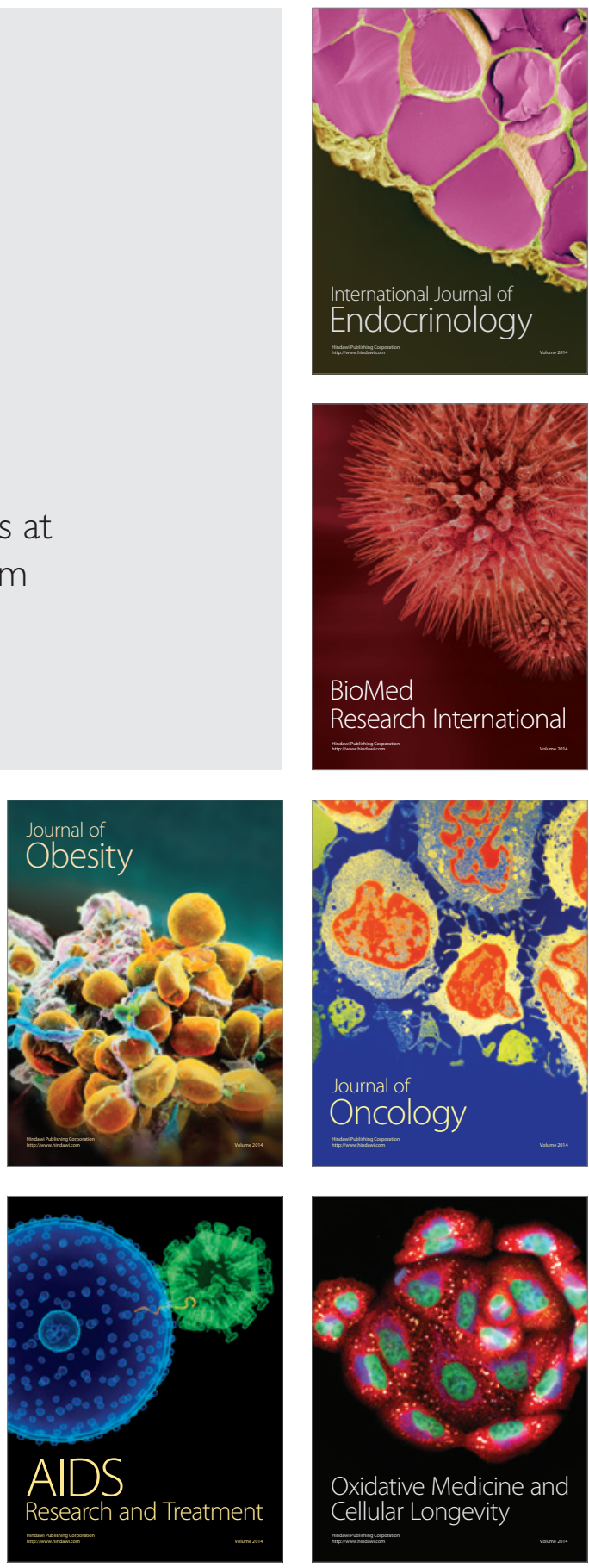